\title{
The relationships between faecal worm egg count and subjectively assessed wool and conformation traits in the Tygerhoek Merino flock
}

\author{
P.A.M. Matebesi-Ranthimo ${ }^{1,2}$, S.W.P. Cloete ${ }^{3,4}$, J.B. van Wyk $^{2}$ \& J.J. Olivier ${ }^{4}$ \\ ${ }^{1}$ National University of Lesotho, P.O. Roma 180, Roma Lesotho \\ ${ }^{2}$ University of the Free State, P.O. Box 339, Bloemfontein 9300, South Africa \\ ${ }^{3}$ University of Stellenbosch, Private Bag X1, Matieland, 7602, South Africa \\ ${ }^{4}$ Directorate Animal Sciences: Elsenburg, Private Bag X1, Elsenburg, 7609, South Africa
}

(Received 30 July 2013; Accepted 13 May 2014; First published online 2 August 2014)

\begin{abstract}
Copyright resides with the authors in terms of the Creative Commons Attribution 2.5 South African Licence.
See: http://creativecommons.org/licenses/by/2.5/za

Condition of use: The user may copy, distribute, transmit and adapt the work, but must recognise the authors and the South African Journal of Animal Science.
\end{abstract}

\begin{abstract}
Subjectively assessed wool and conformation traits form part of the selection objective in wool sheep enterprises. The present study investigated the genetic, phenotypic and environmental correlations for nematode resistance (using faecal worm egg count (FEC)) with subjectively assessed wool and conformation traits. The Merino sheep flock (consisting of four lines) maintained on Tygerhoek Research Farm was used. Fixed effects of selection line, birth type, sex, age of dam in years, year of birth, and sex*birth year interaction had a significant effect on all subjective traits. At genetic level, log transformed FEC was significantly related to wool oil only at $0.18 \pm 0.09$, staple formation at $0.29 \pm 0.10$, and topline at $-0.33 \pm$ 0.11. These correlations suggested that sheep with high FEC are likely to have excessive wool oil, thicker and bulkier staples, and lower scores for topline. Selection for resistance to and resilience against nematodes in Merino sheep thus will not result in marked unfavourable correlated responses in the vast majority of these subjective wool and body conformation traits.
\end{abstract}

Keywords: Linearly assessed traits, faecal worm egg count, conformation, correlations

\# Corresponding author: schalk@elsenburg.com

\section{Introduction}

Merino sheep improvement programmes use objective measurements and subjective assessment for traits that are included in the selection objectives. The use of subjectively assessed traits for selecting breeding sires and dams is still prevalent in South African Merino sheep (Olivier et al., 2006) and in the Dorper, the dominant meat sheep breed in South Africa (Olivier \& Cloete, 2006; Zirishi et al., 2012). In some instances, animals are culled based on these traits without considering unfavourable correlated response in other economically important traits (Olivier \& Cloete 2006; Olivier et al., 2006). The reluctance of farmers to use objective measurements for Merino sheep selection criteria led to the development of a linear-type scoring method (Olivier et al., 1987). Genetic studies of visually assessed traits and their relationships to traits of economic importance followed in Merinos and Afrinos (Snyman \& Olivier, 2002; Matebesi et al., 2009a; b) and more recently in Dorpers (Zishiri et al., 2012).

Research has emphasized the need to include health traits (Miglior, 2004) and indicators of reproduction (Olivier, 1999) in livestock genetic studies to justify their inclusion in breeding programmes. This is because selection for production only may pose potential health risks while compromising reproduction performance (Haile-Mariam et al., 2004). In an attempt to include health traits in genetic studies, research globally has included the genetics of nematode resistance and resilience in sheep flocks, using faecal worm egg count (FEC) as an indicator trait and their relationships with objectively measured wool traits and liveweight (Greeff et al., 1995; Morris et al., 1996; 1997; Cloete et al., 2000; Khusro et al., 2004; Yadav et al., 2006; Cloete et al., 2007; Snyman, 2007). Relationships between FEC and subjectively assessed wool and conformation traits are limited to total fold score (TOT) in South African Merino sheep (Cloete et al., 2000; 2007). Studies of the genetic correlation between FEC and other subjectively assessed wool and conformation traits could not be found elsewhere. It is therefore important to investigate the relationships between subjectively assessed traits and FEC because sheep farmers still use subjective assessment to 
select breeding rams and ewes without knowledge of any correlated response to selection for FEC. The present study involving the relationships of FEC with subjectively assessed wool and conformation traits will form the foundation for future investigations.

Therefore, the objectives of the current study were to investigate the genetic, phenotypic and environmental correlations of FEC with subjectively assessed wool and conformation traits in the Tygerhoek Merino resource flock.

\section{Material and Methods}

The Merino flock that consisted of four lines maintained on the Tygerhoek experimental farm was used as experimental animals in the current study. Further description of the lines and selection practices are provided in a companion paper (Matebesi-Ranthimo et al., 2014). The database consisted of 5891 FEC and between 6789 (topline) and 7167 (three wool traits) subjectively assessed wool and conformation performance records. Description of the FEC data and information regarding the recording, transformation and derived parameters for FEC can be found in the paper by Matebesi-Ranthimo et al. (2014).

Table 1 Linear scale used to assess the subjective fleece and conformation traits in Tygerhoek Merino sheep (adapted from Olivier et al., 1987)

\begin{tabular}{llll}
\hline \multirow{2}{*}{ Trait } & \multicolumn{2}{l}{ Scale of assessment } \\
\cline { 2 - 4 } & $\mathbf{1}$ & $\mathbf{2 5}$ & \\
\hline Subjective wool & & Average & Soft \\
\hline Face cover score (FCS) & Hard & Average & None \\
Pigmentation (PIGM) & Excessive & Ideal & Open faced \\
Woolly face score (WFS) & Woolly faced & Average & Ideal \\
Quality (QUAL) & Poor & Average & Ideal-no variation \\
Regularity of crimp (ROC) & Poor-huge variation & Average & White \\
Colour (COL) & Yellow & Ideal & Excessive \\
Oil (OIL) & None & Average & Thick, blocky \\
Staple formation (STAPL) & Ropy & Average & Thick, white \\
Belly and points (BANDP) & Watery, yellow & & \\
\hline Subjective conformation & & Average & Strong \\
\hline Head general (GEN) & Weak small & Average & Wide \\
Hocks (HOCKS) & Narrow & Average & Wide \\
Front quarters (FQ) & Narrow & Average & Strong \\
Pastern score (PS) & Weak & Average & Ideal-straight \\
Top line (TOPL) & Poor-Hollow & - & Most wrinkly (score=17) \\
Total fold score (TOT) & Plain (score=1) & & \\
& & - & \\
\hline
\end{tabular}

The following partitioning applied to most of traits: 1 - $10=$ poor; 11 - 20 = below average; 21 - 30 = average; $31-40=$ above average and $41-50=$ excellent. The exceptions were woolly face score and oil, which had an intermediate optimum.

Subjectively assessed traits were scored according to a linear scale (Table1) ranging from 1 to 50 (Olivier et al., 1987) at 14 - 16 months of age as described by Matebesi et al. (2009a). At least three experienced judges were used to allocate the scores for individual animals. The scores given by the judges were averaged to provide a final score for that trait in each animal. TOT was scored according to photographic standards for wrinkles on the neck, body and breech.

The data used for the analysis of subjectively assessed wool and conformation traits were edited as described by Matebesi-Ranthimo et al. (2014). Similar procedures to those used by Matebesi-Ranthimo et al. (2014) were applied for analysis in the present study using the ASReml program (Gilmour et al., 2009). Therefore, fixed effects to be included in the operational model for each trait were tested and details of the models are described fully by Matebesi-Ranthimo et al. (2014). The variance components and ratios were estimated as described by Matebesi-Ranthimo et al. (2014). The correlations (genetic, phenotypic and 
environmental) of FEC with subjectively assessed wool and conformation traits were subsequently computed by fitting a series of two-trait and four-trait animal models to derive correlations between traits. These analyses included all the components found to be significant in the single-trait analyses.

\section{Results and Discussion}

The descriptive statistics for subjectively assessed wool and conformation traits are presented in Table 2. Detailed description and non-genetic factors for FEC can be found in a paper by Matebesi-Ranthimo et al. (2014) and will not be repeated here. Preliminary analysis of non-genetic effects indicated that selection line $(1$ - 4), birth type (single/multiple), sex (male/female), age of the dam in years (2 - 6), year of birth (1989 2012) and the sex by birth year interaction had a significant $(P<0.05)$ effect on all subjectively assessed wool and conformation traits. This is in line with previous studies on the same flock (Cloete et al., 1998; Naidoo et al., 2004; Matebesi et al., 2009a).

Table 2 Descriptive statistics of data after editing from Tygerhoek Merino resource flock

\begin{tabular}{llllll}
\hline Trait & N & Mean & SD & CV & Range \\
\hline Subjective wool traits & & & & & \\
\hline FCS & 7167 & 31.29 & 6.50 & 20.77 & $1-50$ \\
PIGM & 7159 & 31.00 & 9.32 & 30.01 & $1-50$ \\
WFS & 6707 & 29.19 & 8.38 & 28.71 & $1-50$ \\
QUAL & 7144 & 31.15 & 8.21 & 26.36 & $1-50$ \\
ROC & 7141 & 32.68 & 7.87 & 24.08 & $1-50$ \\
COL & 7135 & 29.34 & 7.22 & 24.61 & $1-50$ \\
OIL & 7167 & 26.21 & 4.31 & 16.44 & $3-45$ \\
STAPL & 7167 & 28.50 & 5.85 & 20.53 & $2-48$ \\
BANDP & 7165 & 30.68 & 6.40 & 20.86 & $1-50$ \\
\hline Subjective conformation traits & & & & \\
\hline TOT & 6771 & 9.41 & 2.37 & 25.19 & $1-40$ \\
GEN & 6770 & 29.61 & 7.12 & 24.05 & $1-50$ \\
HOCKS & 6770 & 24.94 & 8.30 & 33.30 & $1-48$ \\
FQ & 6771 & 23.39 & 6.69 & 28.60 & $1-49$ \\
PS & 6789 & 32.61 & 6.75 & 20.70 & $1-50$ \\
TOPL & 6769 & 30.45 & 7.50 & 24.63 & $1-50$ \\
\end{tabular}

\footnotetext{
$\mathrm{N}=$ number of records; SD = standard deviation; CV = coefficient of variation; FCS = face cover score; PIGM = pigmentation; WFS = woolly face score; $\mathrm{QUAL}=$ wool quality; ROC = regularity of crimp; $\mathrm{COL}=$ colour; OIL = oil; STAPL = staple formation; BANDP = belly and points; $\mathrm{TOT}=$ total fold score; GEN = general head conformation; HOCKS = hocks; FQ = front quarters; $P S$ = pastern score; TOPL $=$ topline.
}

The selection of models was carried out according to the log likelihood ratio test described in Matebesi-Ranthimo et al. (2014). The model including only the direct additive genetic effect of animal $\left(\sigma^{2}{ }_{a}\right)$ as a random factor fitted the data best for FCS, PIGM, WFS, ROC, COL, OIL, BANDP, HOCKS, FQ and PS. Model 3, which included direct $\left(\sigma^{2}{ }_{a}\right)$ and maternal genetic $\left(\sigma_{m}^{2}\right)$ effects, as well as their covariance $\left(\sigma_{a m}\right)$ as random effects, fitted the data best for STAPL while Model 6 , with only direct additive and dam permanent environmental effects $\left(c^{2}\right)$, was the most appropriate model for GEN and TOPL. In contrast, previous results suggested that ROC, QUAL, COL and TOPL were influenced by direct and maternal genetic effects, as well as their covariance (Matebesi et al., 2009b).

All subjectively assessed wool and conformation traits were heritable with a range between 0.11 for FCS to 0.41 for PIGM for subjective wool traits and from 0.11 for PS and TOPL to 0.36 for TOT for subjective body conformation traits. A study done on the Merino National Progeny Test data (Groenewald et al., 1999) yielded lower heritability estimates for corresponding traits ( 0.17 for COL and BANDP, 0.27 for QUAL, 0.32 for fold score, 0.09 for STAPL and 0.26 for HOCKS). 
Table 3 Log likelihood ratios for random effects models fitted to subjectively assessed wool and conformation traits data of Tygerhoek Merino resource flock with the "best" model in bold

\begin{tabular}{|c|c|c|c|c|c|c|}
\hline & Model 1 & Model 2 & Model 3 & Model 4 & Model 5 & Model 6 \\
\hline \multicolumn{7}{|c|}{ Subjective wool traits } \\
\hline FCS & -5548.95 & -5548.95 & -5548.75 & -5548.95 & $\mathrm{~N} / \mathrm{C}$ & -5548.95 \\
\hline PIGM & -7619.84 & -7619.84 & $\mathrm{~N} / \mathrm{C}$ & -7819.84 & $\mathrm{~N} / \mathrm{C}$ & -7619.84 \\
\hline WFS & -6325.32 & -6325.31 & -6324.66 & -6324.17 & $\mathrm{~N} / \mathrm{C}$ & -6324.17 \\
\hline QUAL & -6710.85 & -6710.62 & -6709.51 & -6710.96 & $\mathrm{~N} / \mathrm{C}$ & -6710.96 \\
\hline ROC & -7093.59 & -7093.59 & $\mathrm{~N} / \mathrm{C}$ & -7093.59 & $\mathrm{~N} / \mathrm{C}$ & -7093.59 \\
\hline $\mathrm{COL}$ & -6091.47 & -6091.22 & -6090.58 & -6090.09 & $\mathrm{~N} / \mathrm{C}$ & -6090.09 \\
\hline OIL & -3369.42 & 3368.34 & -3368.77 & -3368.05 & $\mathrm{~N} / \mathrm{C}$ & -3368.05 \\
\hline STAPL & -4953.59 & -4950.97 & -4948.91 & -4950.74 & 4948.60 & -4951.51 \\
\hline BANDP & -6089.33 & -6089.22 & -6088.88 & -6089.22 & -6088.88 & -6089.33 \\
\hline \multicolumn{7}{|c|}{ Subjective conformation traits } \\
\hline TOT & -8171.07 & -8170.41 & -8169.92 & -8170.14 & $\mathrm{~N} / \mathrm{C}$ & -8170.53 \\
\hline GEN & -5087.45 & -5083.53 & -5083.32 & -5081.93 & $\mathrm{~N} / \mathrm{C}$ & -5081.25 \\
\hline HOCKS & -6641.97 & -6641.80 & -6641.08 & -6641.80 & -6641.08 & -6641.99 \\
\hline $\mathrm{FQ}$ & -5060.56 & -5060.56 & -5059.15 & -5060.35 & -5059.44 & -5060.35 \\
\hline PS & -5056.45 & -5056.44 & -5055.58 & -5056.75 & -5055.44 & -5056.75 \\
\hline TOPL & -5564.41 & -5563.47 & -5562.67 & -5561.63 & -5562.58 & -5561.68 \\
\hline
\end{tabular}

$\mathrm{N} / \mathrm{C}=$ no convergence; FCS $=$ face cover score; PIGM = pigmentation; WFS = woolly face score; $\mathrm{QUAL}=$ wool quality; ROC = regularity of crimp; COL = colour; OIL = oil; STAPL = staple formation; BANDP = belly and points; TOT = total fold score; GEN = general head conformation; HOCKS = hocks; FQ = front quarters;

$\mathrm{PS}=$ pastern score and TOPL = topline.

The heritability estimated currently for OIL (0.21 vs. 0.24$)$ and FQ (0.18 vs. 0.21$)$ was on the lower side compared with reports using Merino data from the national progeny test. Furthermore, some differences of heritability from this investigation and that of Matebesi et al. (2009a) on the same Merino resource flock were observed for QUAL (0.32 vs. 0.49) and ROC ( 0.12 vs. 0.28). These differences may be because of the use of different random effects models. Studies on Australian Merino flocks yielded a slightly higher $\mathrm{h}_{a}^{2}$ of 0.42 for wrinkle score than the current estimate (Mortimer et al., 2009). The latter study also reported slightly higher estimates of $h^{2}$ for front legs and back legs compared with the corresponding traits studied in the present study.

The correlations among subjectively assessed traits did not differ from those reported in the previous study on the same Merino flock and therefore are omitted in the current investigations. Estimates of the genetic $\left(r_{g}\right)$, phenotypic $\left(r_{p}\right)$ and environmental $\left(r_{e}\right)$ correlations from two-trait analyses for log transformed FEC with subjectively assessed wool and conformation traits are presented in Tables 6 and 7, respectively. The correlations involving FEC and subjectively assessed wool and conformation traits obtained from fourtrait analyses did not differ substantially from those obtained from two-trait analysis, and will not be discussed. Genetic correlations between log transformed FEC and subjectively assessed wool and conformation traits were relatively small in magnitude, ranging from -0.33 for TOPL to 0.29 for STAPL. Most were not significant in relation to the corresponding standard errors. Attempts to find comparable literature resulted in only one published negligible genetic correlation of 0.003 between FEC and TOT (Cloete et al., 2007). The absolute magnitude of the corresponding correlation in the present study $(0.15)$ is somewhat higher (Table 7). The direction of the derived correlation suggests that animals with high parasite burdens will also have more wrinkles; that is, the correlation is favourable. However, the comparable environmental and phenotypic correlations were consistently in the $<0.05$ range. 
Table 4 (Co)variance components and ratios for subjectively assessed wool traits in Tygerhoek Merino resource flock

\begin{tabular}{|c|c|c|c|c|c|c|c|c|c|}
\hline & FCS & PIGM & WFS & QUAL & ROC & COL & OIL & STAPL & BANDP \\
\hline \multicolumn{10}{|c|}{ (Co)variance components } \\
\hline$\sigma_{a}^{2}$ & 2.81 & 22.88 & 20.44 & 17.00 & 9.53 & 9.70 & 3.13 & 4.72 & 7.34 \\
\hline$\sigma_{m}^{2}$ & - & - & - & - & - & - & - & 0.56 & - \\
\hline$\sigma_{\mathrm{am}}$ & & - & - & - & - & - & - & -0.80 & - \\
\hline$\sigma_{e}^{2}$ & 25.58 & 33.60 & 32.62 & 34.62 & 36.31 & 25.76 & 12.67 & 19.16 & 26.75 \\
\hline$\sigma_{p}^{2}$ & 28.39 & 56.47 & 53.06 & 51.63 & 45.84 & 35.46 & 15.80 & 24.07 & 34.10 \\
\hline \multicolumn{10}{|c|}{ Variance ratios } \\
\hline $\mathrm{h}_{\mathrm{a}}^{2}$ & 0.10 & 0.41 & 0.39 & 0.33 & 0.21 & 0.27 & 0.20 & 0.20 & 0.22 \\
\hline SE & 0.02 & 0.03 & 0.03 & 0.02 & 0.02 & 0.02 & 0.02 & 0.02 & 0.02 \\
\hline$h_{m}^{2}$ & - & - & - & - & - & - & - & 0.04 & - \\
\hline SE & - & - & - & - & - & - & - & 0.01 & - \\
\hline$r_{a m}$ & - & - & - & - & - & - & - & -0.38 & - \\
\hline SE & - & - & - & - & - & - & - & 0.13 & - \\
\hline
\end{tabular}

$\sigma^{2}{ }_{a}=$ direct additive genetic variance; $\sigma_{m}^{2}=$ maternal additive genetic variance; $\sigma^{2}=$ residual variance;

$\sigma^{2}{ }_{a m}=$ covariance between direct and maternal additive variance; $h_{a}^{2}=$ direct heritability; $h_{m}^{2}=$ maternal heritability;

$\mathrm{r}_{\mathrm{am}}=$ genetic correlation between direct, maternal additive genetic effects; SE = standard error.

See Table 1 for other abbreviations.

Table 5 (Co)variance components and ratios for subjective conformation traits in Tygerhoek Merino resource flock

\begin{tabular}{|c|c|c|c|c|c|c|}
\hline & TOT & GEN & HOCKS & FQ & PS & TOPL \\
\hline \multicolumn{7}{|c|}{ (Co)variance components } \\
\hline$\sigma_{a}^{2}$ & 1.56 & 10.90 & 18.46 & 6.18 & 3.96 & 4.92 \\
\hline$\sigma_{p e}^{2}$ & - & 1.46 & - & - & - & 1.18 \\
\hline$\sigma_{e}^{2}$ & 2.92 & 25.16 & 41.69 & 29.49 & 31.92 & 37.04 \\
\hline$\sigma_{p}^{2}$ & 4.48 & 37.52 & 60.16 & 35.68 & 35.88 & 43.140 \\
\hline \multicolumn{7}{|c|}{ Variance ratios } \\
\hline $\mathrm{h}_{\mathrm{a}}^{2}$ & 0.35 & 0.29 & 0.30 & 0.17 & 0.11 & 0.11 \\
\hline SE & 0.02 & 0.03 & 0.03 & 0.02 & 0.02 & 0.02 \\
\hline$c_{p e}^{2}$ & - & 0.04 & - & - & - & 0.03 \\
\hline SE & - & 0.01 & - & - & - & 0.01 \\
\hline
\end{tabular}

$\sigma^{2}{ }_{c p e}=$ permanent environmental variance; $c^{2}{ }_{p e}=$ permanent environmental effect; FCS = face cover score;

$\mathrm{PIGM}=$ pigmentation; WFS = woolly face score; $\mathrm{QUAL}=$ wool quality; ROC = regularity of crimp; $\mathrm{COL}=$ colour;

OIL = oil; STAPL = staple formation; BANDP = belly and points; TOT = total fold score;

GEN = general head conformation; HOCKS = hocks; FQ = front quarters; PS = pastern score; TOPL = topline.

At the genetic level, only log transformed FEC was significantly related to OIL and STAPL, among all the subjectively assessed wool traits. The positive correlation between log transformed FEC and OIL suggested that sheep with a high quantity of internal nematodes are likely to have wool with excessive oil. South African research has indicated that excessive wool oil has an unfavourable effect on handling by increasing its harshness (Venter, 1981). Excessive oil also affects the appearance of wool owing to an undesirable discolouration and results in a lower wool clean yield (Venter, 1981). The positive genetic correlation of FEC with STAPL suggests that animals with higher parasite burdens were likely to have thicker and blockier staples. This genetic correlation may influence selection for wool quantity in a strategy that seeks to improve fleece weight while reducing FEC, as STAPL was favourably correlated to clean fleece 
weight on the genetic level (0.39; Matebesi et al., 2009b). In contrast, genetic correlations of STAPL with fibre diameter (FD: 0.59) and the coefficient of variation of fibre diameter (CVFD: 0.49) were unfavourable according to these authors. The direction of the derived genetic correlation between FEC and STAPL may thus be of concern as far as wool quantity is concerned. On the other hand, the possible deterioration of STAPL scores resulting from selection for reduced FEC could potentially benefit wool quality. Phenotypic correlations were significant and negative for FEC with WFS and ROC. In contrast, positive phenotypic correlations were observed for FEC with OIL, STAPL and BANDP in the current study.

Table 6 Genetic, phenotypic and environmental ( \pm SE) correlations between faecal egg count and subjective wool traits in Tygerhoek Merino flock

\begin{tabular}{lccc}
\hline \multicolumn{1}{c}{ Trait } & Genetic $\left(r_{\mathrm{g}}\right)$ & Environment $\left(r_{\mathrm{e}}\right)$ & Phenotypic $\left(r_{\mathrm{p}}\right)$ \\
\hline FEC(log+100) X & & & $-0.06 \pm 0.01$ \\
\hline Face cover score (FCS) & $-0.25 \pm 0.13$ & $-0.05 \pm 0.02^{\star}$ & $-0.02 \pm 0.02$ \\
Pigmentation (PIGM) & $-0.09 \pm 0.08$ & $-0.01 \pm 0.03$ & $-0.04 \pm 0.01^{\star}$ \\
Woolly face score (WFS) & $-0.11 \pm 0.08$ & $-0.03 \pm 0.02$ & $-0.01 \pm 0.02$ \\
Quality (QUAL) & $-0.11 \pm 0.09$ & $0.02 \pm 0.02$ & $-0.02 \pm 0.01^{\star}$ \\
Regularity of crimp (ROC) & $-0.18 \pm 0.10$ & $0.02 \pm 0.02$ & $-0.002 \pm 0.01$ \\
Colour (COL) & $-0.10 \pm 0.08$ & $0.03 \pm 0.02$ & $0.03 \pm 0.01^{\star}$ \\
Oil (OIL) & $0.18 \pm 0.09^{\star}$ & $-0.01 \pm 0.02$ & $0.05 \pm 0.01^{\star}$ \\
Staple formation (STAPL) & $0.29 \pm 0.10^{\star}$ & $0.00 \pm 0.02$ & $0.04 \pm 0.01^{\star}$ \\
Belly and points (BANDP) & $0.13 \pm 0.10$ & $0.02 \pm 0.02$ & \\
\hline
\end{tabular}

ॠ = significant correlation.

The subjectively assessed conformation traits were largely independent of FEC at the genetic level. The only noteworthy genetic correlation of -0.33 occurred between TOPL and FEC. This correlation suggests that low scores for TOPL are likely to be found in individuals that have a high population of intestinal nematodes, rendering the correlation favourable. Phenotypic and environmental correlations of FEC with subjective conformation traits were mostly negative (i.e. favourable), significant in a number of instances, but consistently small in magnitude at $<0.10$.

Table 7 Genetic, phenotypic and environmental ( \pm SE) correlations between faecal egg count and subjective conformation traits in Tygerhoek Merino flock

\begin{tabular}{lccc}
\hline & Genetic $\left(r_{\mathrm{g}}\right)$ & Environment $\left(r_{\mathrm{e}}\right)$ & Phenotypic $\left(r_{\mathrm{p}}\right)$ \\
\hline FEC(log+100) X & & & \\
\hline Total fold score (TOT) & $0.15 \pm 0.08$ & $-0.04 \pm 0.02^{\star}$ & $0.01 \pm 0.016$ \\
General head conformation (GEN) & $0.02 \pm 0.09$ & $-0.05 \pm 0.02^{\star}$ & $-0.04 \pm 0.02^{\star}$ \\
Hocks(HOCKS) & $0.03 \pm 0.09$ & $-0.07 \pm 0.02^{\star}$ & $-0.05 \pm 0.01^{\star}$ \\
Front quarters (FQ) & $-0.13 \pm 0.11$ & $-0.03 \pm 0.02$ & $-0.05 \pm 0.01^{\star}$ \\
Pastern score (PS) & $-0.16 \pm 0.13$ & $0.03 \pm 0.02$ & $0.01 \pm 0.01$ \\
Topline (TOPL) & $-0.33 \pm 0.11^{\star}$ & $-0.04 \pm 0.02^{\star}$ & $-0.08 \pm 0.01^{\star}$ \\
\hline * significant correlation & &
\end{tabular}

\section{Conclusion}

The study confirmed previous results from the same flock that subjective wool and body conformation traits are heritable and variable, and should thus respond to selection, if desired. The majority of subjective traits were not related to FEC at genetic level, and two of the three significant genetic correlations (those for OIL and TOPL) were favourable. The positive genetic correlation of FEC with STAPL suggests that wool 
weight may be compromised by selection for reduced FEC, but that the quality of the wool (as reflected by FD and CVFD) may be enhanced. There was thus limited evidence of subjectively assessed traits being impaired by selecting South African sheep flocks for resistance to gastro-intestinal nematodes, as reflected by FEC.

\section{Acknowledgements}

The usual dedicated technical assistance of E. du Toit and stimulating discussion with the Elsenburg animal sciences staff, as well as the dedicated input of Tygerhoek farm workers, are highly appreciated. CIVA innovation management, THRIP funding of the NRF, the NRF, the South African wool industry, the National University of Lesotho and Organisation for Women in Science for the Developing World (OWSDW) are gratefully acknowledged for co-funding the current study.

\section{References}

Cloete, S.W.P., Olivier, J.J., Snyman, M.A. \& Du Toit, E., 1998. Genetic parameters and trends in a selection experiment for increased clean fleece weight involving South African Merinos. Aust. J. Exp. Agric. 38, 427-432.

Cloete, S.W.P., Dreyer, F.H. \& Du Toit, E., 2000. Faecal nematode egg count in Merinos sheep following natural challenge. S. Afr. J. Anim. Sci. 30 (Suppl. 1), 24-25.

Cloete, S.W.P., Olivier, J.J., Du Toit, E. \& Dreyer, F.H., 2007. Genetic analysis of faecal worm egg count in South Africa Merinos under natural challenge. S. Afr. J. Anim. Sci. 37, 237-247.

Gilmour, A.R., Gogel, B.J., Cullis, B.R., Welham, S.J. \& Thompson, R., 2009. ASREML-User Guide Release 3.0 VSN International Ltd, Hemel Hempstead, HPI IES, UK.

Greeff, J.C., Karlsson, L.J.E. \& Harris, J.F., 1995. Heritability of faecal worm egg count at different times of the year in a Mediterranean environment. Proc. Aust. Assoc. Anim. Breed. Genet. 11, 117-121.

Groenewald, P.G.J., Olivier, J.J. \& Olivier, W.J., 1999. Heritability estimates for Merino sheep obtained from a national progeny test. S. Afr. J. Anim. Sci. 29, 174-178.

Haile-Marian, M., Bowman, P.J. \& Goddard, M.E., 2004. Genetic parameter estimates for fertility traits and their correlation with production, type, work ability, liveweight, survival index and cell count. Aust. J. Agric. Res. 55, 77-87.

Khusro, M., Van der Werf, J.H.J., Brown, D.J. \& Ball, A., 2004. Across flock (co)variance components for faecal worm egg count, liveweight, and fleece traits in Australian Merinos. Livest. Prod. Sci. 91, 35-43.

Matebesi, P.A., Van Wyk, J.B. \& Cloete, S.W.P., 2009a. Genetic parameters for subjectively assessed wool and conformation traits in the Tygerhoek Merino flock. S. Afr. J. Anim. Sci. 39, 176-187.

Matebesi, P.A., Van Wyk, J.B. \& Cloete, S.W.P., 2009b. Relationships of subjectively assessed wool and conformation traits with objectively measured wool and liveweight traits in Tygerhoek Merino flock. S. Afr. J. Anim. Sci. 39, 188-196.

Matebesi-Ranthimo, P.A.M., Cloete, S.W.P., Van Wyk, J.B. \& Olivier, J.J., 2014. Genetic parameter and relationships of faecal worm egg count with objectively measured wool traits in the Tygerhoek Merino flock. S. Afr. J. Anim. Sci. 44, 178-188.

Miglior, F., 2004. Overview of different breeding objectives in various countries. Proc. $11^{\text {th }}$ WHFF meeting, session 4, 7-11.

Morris, C.A., Clarke, J.N., Watson, T.G., Wrigglesworth, A.L. \& Dobbie, J.L., 1996. Faecal egg count and food intake comparison of Romney single-trait selection and control lines. N. Z. J. Agric. Res. 39, 371-378.

Morris, C.A., Bisset, S.A., Vlassoff, A., Baker, R.L., Watson, T.G. \& Wheeler, M., 1997. Yearling and ewe fleece weights in Romney and Perendale flocks selected for divergence in faecal nematode egg count. Proc. Assoc. Advmn. Anim. Breed. Genet. 12, 50-53.

Mortimer, S.I., Robinson, D.L., Atkins, K.D., Brien, F.D., Swan, A.A., Taylor, P.J. \& Fogarty, N.M., 2009. Genetic parameters for visually assessed traits and their relationships to wool production and liveweight in Australian Merino sheep. Anim. Prod. Sci. 49, 32-42.

Naidoo, P., Cloete, S.W.P. \& Olivier, J.J., 2004. Heritability estimates and correlations between subjectively assessed and objectively measured fleece traits in Merino sheep. S. Afr. J. Anim. Sci. 34, 38-40.

Olivier, J.J., 1999. The South African Merino performance testing scheme. Proc. Assoc. Advmt. Anim. Breed. Gen. 15, 119-124.

Olivier, J.J. \& Cloete, S.W.P., 2006. Genetic analysis of South African Dorper sheep. Proc. World. Congr. Gen. Appl. Livest. Prod. Bello Horizonte, 13-18 August, 2006.

Olivier, J.J., Delport, G.J., Erasmus, G.J. \& Eksteen, T.J., 1987. Linear type scoring in Merino sheep. Karoo Agric. 3, 1-4. 
Olivier, W.J., Olivier, J.J. \& Greyling, A.C., 2006. Correlations of subjectively assessed traits of fine wool Merino sheep with production and reproduction traits. Proc. $41^{\text {st }}$ S. Afr. Soc. Anim. Sci. 3-6 April 2006, Bloemfontein, South Africa.

Snyman, M.A., 2007. Prospects for the utilization of variation in parasite resistance among individual sheep within a flock. Grootfontein Agric. 7 (1), 29-34.

Snyman, M.A. \& Olivier, W.J., 2002. Correlations of subjectively assessed fleece and conformation traits with production and reproduction in Afrino sheep. S. Afr. J. Anim. Sci. 32, 88-96.

Venter, J.J., 1981. Yolk in wool. Karoo Agric. 2 (2), 35-38.

Yadav, N.K., Mandal, A., Sharma, D.K., Rout, P.K. \& Roy, R., 2006. Genetic studies on faecal egg count and packed cell volume following natural Haemonchus contortus infection and their relationships with liveweight in Muzaffarnagari sheep. Asian-Austral. J. Anim. Sci. 19, 1525-1528.

Zishiri, O.T., Cloete, S.W.P., Olivier, J.J. \& Dzama, K., 2012. Genetic parameter estimates for subjectively assessed and objectively measured traits in South African Dorper sheep. Small Rumin. Res. 109, 84-93. 